\title{
Papilomavírus bovino tipo 2 na etiologia da \\ hematúria enzoótica bovina ${ }^{1}$
}

\section{Bovine papillomavirus type 2 in enzootic haematuria aetiology}

\author{
Sheila Rezler Wosiacki ${ }^{2}$; Antônio Carlos Faria dos Reis ${ }^{3}$; \\ Alice Fernandes Alfieri ${ }^{4}$; Amauri Alcindo Alfieri ${ }^{*}$
}

\begin{abstract}
Resumo
A hematúria enzoótica (HE) bovina é de ocorrência mundial e apresenta caráter endêmico em regiões com pastagens infestadas com samambaia (Pteridium aquilinum). A HE é uma doença crônica caracterizada por sinais clínicos de hematúria intermitente, anemia e emagrecimento progressivo e por lesões hemorrágicas, hiperplásicas e neoplásicas da mucosa da bexiga. Apesar da intoxicação pela samambaia estar relacionada à etiologia da HE, mais recentemente a infecção pelo papilomavírus bovino tipo 2 (BPV-2) também tem sido avaliada. Estudos demonstram que a presença do BPV-2, associada à ação dos compostos carcinogênicos da samambaia, leva à progressão maligna das lesões na mucosa vesical responsáveis pelos quadros clínicos observados na HE. Nesta revisão são apresentadas as principais evidências do envolvimento do BPV-2 na etiologia da HE, bem como métodos de diagnóstico e profilaxia desta doença que ocasiona prejuízos econômicos consideráveis à pecuária bovina brasileira.

Palavras chave: Bovinos, Hematúria Enzoótica, Papilomavírus Bovino Tipo 2, Samambaia.
\end{abstract}

\begin{abstract}
Bovine enzootic haematuria (EH) occurs worldwide and is endemic in regions with bracken fern (Pteridium aquilinum) infested grassland. EH is chronic disease that is characterized by clinical signs of intermitent haematuria, anemia and progressive emaciation and haemorragic, hyperplasic and neoplasic lesions of urinary bladder. Although bracken fern intoxication has been related to EH, most recent bovine papillomavirus type 2 (BPV-2) infection has been also assessed. Some researches has shown that the presence of BPV-2 in association with bracken fern carcinogenic compound leads to the malignant progression of urinary bladder lesions that cause the clinical signs of $\mathrm{EH}$. In this review the major evidence of BPV-2 involviment in the aetiology of EH is presented along with diagnostic methods and prophylaxis of this disease that causes considerable economic losses in brazilian cattle breeding.

Key words: Bovine, Enzootic Haematuria, Bovine Papillomavirus Type 2, Bracken Fern.
\end{abstract}

1 Apoio Financeiro: CNPq, CAPES e CPG/UEL.

2 Aluna do Programa de Pós-graduação em Ciência Animal (área de concentração: Sanidade Animal; nível: Mestrado), Universidade Estadual de Londrina (UEL).

${ }^{3}$ Laboratório de Anatomia Patológica, Departamento de Medicina Veterinária Preventiva (DMVP), Centro de Ciências Agrárias (CCA), UEL.

${ }^{4}$ Laboratório de Virologia Animal, DMVP, CCA, UEL, Londrina, Paraná, Brasil. Caixa Postal: 6001. Tel.: + 43-3371-4068; Email: alfieri@uel.br

* Autor para correspondência. 


\section{Introdução}

A hematúria enzoótica bovina (HE) é uma doença crônica de bovinos que acarreta consideráveis perdas econômicas, tanto de forma direta quanto indireta. De ocorrência mundial, a HE apresenta prevalência variada em áreas endêmicas, podendo alcançar até $90 \%$ em animais com idade superior a dois anos. A doença tem longo período de evolução e, clinicamente, caracteriza-se por hematúria intermitente que conduz à anemia e ao emagrecimento progressivo. $\mathrm{O}$ quadro anatomopatológico da HE caracteriza-se por lesões hemorrágicas e hiperplásicas da mucosa vesical que, com freqüência, evoluem para neoplasias (OLSON et al., 1959; POLACK, 1990; CAMPO et al., 1992; DURÃO et al., 1995).

Historicamente, devido a forte associação geográfica que existe entre a presença da samambaia (Pteridium aquilinum) nas pastagens e o aparecimento da HE, esta doença sempre esteve associada com a alimentação dos bovinos em pastagens infestadas por esta planta. Em relatos recentes, a infecção com o papilomavírus bovino tipo 2 (BPV-2) também está sendo associada aos quadros clínicos da HE. Apesar das relações entre o BPV-2 e os tumores de bexiga em bovinos já estarem documentadas, o envolvimento viral na etiologia da HE ainda tem sido pouco estudado. Algumas evidências epidemiológicas sugerem que a progressão para a malignidade das lesões iniciais seja dependente de inter-relações entre o papilomavírus e compostos mutagênicos e imunodepressivos presentes na samambaia (HOPKINS, 1986; CAMPO et al., 1994; CAMPO, 1997; SANTOS et al., 1998).

A té o momento não há um tratamento efetivo para a HE. A retirada total da samambaia da dieta pode propiciar uma lenta recuperação desde que não existam lesões neoplásicas avançadas. Com a comprovação do envolvimento do BPV-2 na etiologia da HE, abre-se a perspectiva do emprego de vacinas específicas no controle imunoprofilático desta importante doença dos bovinos (HOPKINS, 1986; POLACK, 1990).
O diagnóstico do BPV-2 por meio de técnicas convencionais é de difícil realização, particularmente pela não adaptação do virus em sistemas de replicação in vitro em culturas celulares. Os avanços nos métodos de diagnóstico molecular tornaram possível o diagnóstico da infecção pelo papilomavírus a partir da identificação do DNA viral por técnicas de hibridação molecular ou pela reação em cadeia pela polimerase (PCR). Outras técnicas convencionais como a citologia, a histopatologia e a imunoistoquímica também podem ser utilizadas, porém a menor sensibilidade e, em algumas situações, a demora para a conclusão dos resultados estimularam o desenvolvimento dos métodos moleculares para o diagnóstico do BPV (BLOCH et al., 1997; GROSS; BARRASSO, 1999).

Esta revisão de literatura tem por objetivo descrever alguns aspectos relacionados à etiologia da HE, com ênfase ao BPV-2 associado aos compostos tóxicos presentes na samambaia.

\section{Aspectos clínicos}

A HE é caracterizada pela passagem de sangue para a urina. As primeiras manifestações clínicas ocorrem em animais adultos, em geral entre três e cinco anos de idade, sem preferência por sexo ou raça. As lesões mais frequientes são de natureza inflamatória, hiperplásica, metaplásica e/ou neoplásica na mucosa da bexiga, que conduzem a hemorragias, na forma de hematúria intermitente. Os períodos entre os episódios de hematúria variam de semanas a meses e a doença evolui devido às crises de hematúria associada à poliúria e disúria, intercaladas por longos períodos de remissão. A fase de hematúria é variável, a quantidade de sangue perdida é inconstante e a hemorragia conduz à anemia, ao emagrecimento e, em alguns casos, a acentuada proteinúria. A anemia geralmente é normocítica e normocrômica devido à diminuição do número de eritrócitos ocasionada pela perda de sangue. A morte ocorre pela perda de sangue e anemia, pela caquexia ou por metástase das neoplasias em outros órgãos e tecidos e, principalmente, por anemia 
hemorrágica. A evolução clínica da enfermidade pode ser insidiosa e intermitente. Em alguns casos podem ocorrer melhoras passageiras e reagudização, de acordo com a intensidade das hemorragias vesicais. Principalmente nos machos, a eliminação de urina pode ser interrompida por coágulos de sangue, podendo ocorrer complicações graves como a hidronefrose e infecções ascendentes das vias urinárias (RAJENDRAN et al., 1983; POLACK, 1990; MONOGHAN; BOY, 1993; DURÃO et al., 1995).

O diagnóstico da HE deve basear-se no histórico, no quadro clínico e, sobretudo nas lesões. No entanto, este diagnóstico deve levar em consideração também a infecção do trato urinário, que é a outra condição principal de causa de hematúria em bovinos. A piúria e a presença de grande número de bactérias na urina diferenciam a infecção da intoxicação crônica pela samambaia. Outras doenças que são acompanhadas de hematúria ou de hemoglobinúria como o carbúnculo hemático, hemoglobinúria puerperal, hemoglobinúria bacilar, leptospirose e a babesiose/anaplasmose também devem ser consideradas no diagnóstico diferencial (MONOGHAN; BOY, 1993).

\section{Aspectos anatomopatológicos}

A lesão inicial observada na HE é a cistite hemorrágica, resultando em hematúria persistente que parece surgir a partir de hemorragias do córion, sem soluções de continuidade na mucosa. Ao exame macroscópico são observadas manchas de coloração escura, sem deformação superficial. As mudanças histopatológicas do epitélio de transição, incluindo a proliferação e a descamação epitelial, fazem com que o epitélio se apresente enrugado e com crescimento irregular, caracterizando infiltrações em coluna do epitélio no interior da lâmina própria, conhecidas como ninhos de "Brünn". Na lâmina própria, infiltrados focais com células inflamatórias mononucleares são encontrados com freqüência, além da reação proliferativa e pleomórfica das células epiteliais. A presença de corpúsculos de inclusão acidófilos nas células da bexiga sugere a possibilidade do envolvimento de agente viral (PACHAURI; SHARMA; JOSHI, 1981; HOPKINS, 1986; THOMSON, 1990; DURÃO et al., 1995).

Com a evolução das lesões iniciais podem ocorrer neoplasias epiteliais que ocupam espaço e, com frequiência, ocasionam ulcerações na mucosa. Com base no pleomorfismo e nas variedades teciduais as neoplasias podem ser classificadas em epiteliais, mesenquimais e mistas, onde as mais comuns são as mistas, que apresentam diferentes composições. Os papilomas, adenomas, adenocarcinomas, carcinomas uroteliais, carcinomas de células escamosas, fibromas, hemangiomas e hemangiossarcomas são as neoplasias simples mais comuns na $\mathrm{HE}$ (PACHAURI; SHARMA; JOSHI, 1981; THOMSON, 1990; NIELSEN; MOULTON, 1990; CAMPO et al., 1992).

\section{Aspectos etiológicos}

A etiologia da HE ainda é incerta e numerosos fatores já foram sugeridos incluindo deficiências nutricionais, ingestão de plantas tóxicas (Pteridium aquilinum, $P$. esculentum, $P$. revolutum, Cheilanthes sieberi, Encephalartos hildebrandtii, Ranunculus montana, R. acris, Climatis vitalba), falta ou excesso de molibdênio no solo e agentes infecciosos como bactérias (Corynebacterium renale), fungos (Fusarium spp), protozoários e endoparasitas. Atualmente o BPV, associado a compostos carcinogênicos de plantas tóxicas, particularmente a Pteridium aquilinum, é a etiologia mais provável da HE (PACHAURI; SHARMA; JOSHI, 1981; HOPKINS, 1986; NIELSEN; MOULTON, 1990).

\section{Samambaia}

A HE apresenta caráter enzoótico em áreas que reúnem condições ideais para o crescimento da planta Pteridium aquilinum conhecida como samambaia ou samambaia-do-campo, que se desenvolve em solos pobres, ácidos, com baixos níveis de cálcio e de 
fósforo e com umidade elevada. A samambaia é uma pteridófita do gênero Pteridium, espécie aquilinum, e no Brasil é encontrada apenas a subespécie caudatum, variedade arachnoideum. Trata-se de uma planta invasora, presente em todas as regiões com clima tropical e temperado, que freqüentemente infesta pastagens, solos cultivados e capoeiras e que se manifesta com exuberância somente em ambientes onde há pouca competição. No Brasil, sua presença é registrada em praticamente todos os Estados (HOPKINS, 1990; POLACK, 1990; DURÃO et al., 1995).

Devido à forte associação entre a presença da samambaia e a ocorrência da HE, relatada pela primeira vez em 1942, esta planta é considerada a etiologia da doença. Com a alteração da flora e desaparecimento da samambaia das pastagens é possível a redução no surgimento de novos casos de HE. A reprodução experimental dos quadros clínicos da HE em bovinos jovens e em cobaios alimentados com samambaia já foi relatada (RAJENDRAN et al., 1983; HOPKINS, 1986; BRINGUIER et al., 1995).

A samambaia é conhecida por apresentar em sua composição diversas substâncias mutagênicas, carcinogênicas e imunossupressivas. A toxicidade da samambaia é comprovada experimentalmente, no entanto, a patogenia da HE ainda não está totalmente esclarecida. Esta planta é considerada carcinogênica quando ingerida por bovinos e ratos desde a década de 60, mas existem relatos que não ratificam esta afirmação (POLACK, 1990; CAMPO et al., 1992; SANTOS et al., 1998).

Substâncias potencialmente mutagênicas e/ou carcinogênicas foram isoladas da samambaia, incluindo a quercetina, ptaquilosídeos, a-ecdysone, ácido shikímico, aquilídeo A, tanino, prunasina e canferol. A carcinogenicidade tem sido atribuída a quercetina, ao ácido shikímico e ao ptaquilosídeo, porém a baixa frequiência de atividade citotóxica destes compostos sugere que não sejam os prováveis agentes etiológicos diretos da intoxicação pela samambaia em bovinos. A natureza dos carcinógenos não foi completamente elucidada e nenhum dos cons- tituintes tóxicos isolados foi capaz de reproduzir, individualmente, todas as síndromes típicas desta intoxicação. A maioria dos experimentos que descrevem a atividade carcinogênica da samambaia envolve animais de laboratório. São poucos os trabalhos que relatam os efeitos destes componentes em bovinos adultos (HOPKINS, 1986; POLACK, 1990; NGOMOU; JONES, 1996; CAMPO, 1997).

Apesar da baixa palatabilidade, a intoxicação natural pela samambaia em bovinos pode ocorrer sob várias condições que favorecem a sua ingestão acidental, em fenos contaminados, ou a sua utilização como alimento pela escassez de pastagens devido ao superpastoreio, secas, geadas ou queimadas. Em bovinos podem ser observadas três formas clínicas da intoxicação pela samambaia. Uma forma aguda, conhecida como diátese hemorrágica, e duas formas crônicas, a HE e o tumor do trato digestório superior (POLACK, 1990; GAVA, 1993).

A forma aguda da doença ocorre geralmente no período do inverno, após uma rápida e grande ingestão da samambaia e, com maior freqüência, afeta animais com idade inferior a dois anos. $\mathrm{O}$ quadro típico da doença caracteriza-se por febre alta, diátese hemorrágica, erosões e úlcera nas narinas e na mucosa do aparelho digestório, anemia e morte em poucos dias. Este quadro é associado a uma grave depressão da atividade da medula óssea (TOKARNIA; DÖBEREINER ; CANELLA, 1967; HOPKINS, 1990).

As primeiras manifestações clínicas da HE ocorrem em animais adultos, após um longo período de exposição à samambaia. A HE pode ainda ocorrer em associação com neoplasias do trato digestório. Esta forma clínica está também etiologicamente associada à infecção pelo BPV-2 (RAJENDRAN et al., 1983; HOPKINS, 1986; DURÃO et al., 1995).

Os tumores do trato digestório superior obstruem a passagem de alimentos e ao exame clínico são observados sinais de disfagia, regurgitação, dilatação do esôfago proximal à massa tumoral, perda de peso e timpanismo crônico recidivante. A ocorrên- 
cia destes tumores, embora de etiologia não confirmada experimentalmente, tem sido atribuída à ingestão da samambaia e a uma possível associação etiológica com o BPV-4. Uma percentagem significativa dos animais com lesões do trato digestório superior também apresenta lesões neoplásicas na bexiga urinária (THOMSON, 1990; POLACK, 1990; CAMPO et al., 1992; SCHUCH, 1998).

\section{Papilomavírus bovino}

Os papilomavírus, associados a diferentes formas de carcinogênese em mamíferos e aves, estão classificados na família Papillomaviridae, gênero Papillomavirus. Os papilomavírus constituem um grupo muito heterogêneo de vírus e diferentes genótipos são associados a diferentes tipos de lesões. De acordo com a estrutura e a composição do DNA são conhecidos seis tipos de BPV, relacionados com o aparecimento de tumores em diferentes locais e com estruturas macro e microscópicas distintas. O BPV apresenta dois grupos. O grupo A compreende os fibropapilomavírus (BPV-1, 2 e 5) e o grupo B compreende os papilomavírus epiteliotrópicos (BPV3, 4 e 6). A infecção com os fibropapilomavírus ocasiona uma transformação inicial dos fibroblastos subepiteliais, seguida por acantose e então papilomatose, enquanto que a infecção com os papilomavírus epiteliotrópicos induz papilomas epiteliais sem o envolvimento dos fibroblastos. O BPV-1 e o BPV-2 são os principais agentes de fibropapilomas cutâneos. O BPV-1 também pode causar fibropapilomas nos tetos e no pênis e o BPV-2 fibropapilomas no trato digestório. O BPV-5 causa fibropapilomas em forma de grão de arroz no úbere; e os BPV-3, 4 e 6 foram isolados de papilomas epiteliais cutâneos, papilomas do epitélio do trato digestório e papiloma epitelial de tetos, respectivamente (CAMPO, 1987; BLOCH; BREEN; SPRADBROW, 1994; CAMPO, 1997; SCHUCH, 1998; VAN REGENMORTEL et al., 2000).

O BPV é um pequeno vírus oncogênico, não envelopado, com morfologia icosaédrica e diâmetro de
52-55 nm. O capsídeo apresenta 72 capsômeros (60 hexaméricos e 12 pentaméricos) e o ácido nucléico é composto por DNA de fita dupla circular com massa molecular de 5.0 × $10^{6}$ daltons e cerca de $8 \mathrm{kpb}$ (STRINGFELLOW et al., 1988).

O genoma do BPV contém dois segmentos principais, sendo cada um constituído por uma série de regiões ou ORFs (opening reading frames - janelas abertas de leitura) que codificam as proteínas virais. Os segmentos E (early - precoce) 1 a 8 , que representam $45 \%$ do genoma viral, codificam proteínas que são necessárias para os processos iniciais da replicação viral e para a transformação da célula hospedeira. Os segmentos L (late - tardio) 1 e 2, são os genes que codificam as proteínas estruturais que compõem o capsídeo viral e representam $40 \%$ do genoma. Entre os segmentos L e E existe um terceiro segmento que corresponde a $15 \%$ do genoma e que codifica elementos regulatórios da replicação viral (CAMPO et al., 1994).

O BPV é adquirido por inoculação cutânea direta ou por soluções de continuidade da pele. A replicação viral ocorre nas células basais do epitélio estimulando a divisão celular, hiperproliferação e também induzindo o crescimento excessivo dessas células, formando as verrugas ou papilomas que geralmente regridem sem causar problemas clínicos em seus hospedeiros. O BPV induz tumores benignos e, eventualmente, quando fatores genéticos ou ambientais estão envolvidos, pode resultar em conversão maligna (CAMPO, 1987; STRINGFELLOW et al., 1988).

Ainda não está esclarecido como fatores carcinogênicos e agentes promotores estão envolvidos em diferentes estádios do desenvolvimento de papilomas e carcinomas. Porém, já foram descritas duas etapas do mecanismo da carcinogênese, a iniciação e a promoção, que têm componentes independentes (REDDY; FIALKOW, 1983).

A presença do BPV-2 em papilomas e carcinomas na bexiga de bovinos, associados à $\mathrm{HE}$, foi inicialmente sugerida com base na detecção de corpúsculos de inclusão, característicos do vírus, em célu- 
las tumorais. Posteriormente foi relatado que tumores de bexiga induzem lesões similares quando injetados em animais saudáveis e que animais com carcinoma do trato digestório apresentam alta prevalência de papilomas na região tumoral. No entanto, as toxinas da samambaia também são capazes de produzir tumores em animais de laboratório livres da infecção pelo BPV-2, e este, isoladamente, foi capaz de produzir neoplasias na bexiga de bezerros que não tinham acesso à samambaia. Resultados de vários experimentos confirmaram que tanto o vírus quanto a samambaia estão envolvidos na carcinogênese da bexiga (JARRETT, 1978; PACHAURI; SHARMA; JOSHI, 1981; HOPKINS, 1986; MOURA et al., 1988; POLACK, 1990, CAMPO et al., 1992; SANTOS et al., 1998). Reddy e Fialkow (1983) descreveram que, diferentemente das induções por carcinógenos isolados, o BPV induz a iniciação e a promoção dos tumores em conjunto com compostos da samambaia. A rota da infecção do BPV-2 para a bexiga ainda não é conhecida, mas já foi comprovado que o BPV-2 pode ser transmitido de forma vertical (CAMPO et al., 1992).

Apesar de poucos estudos envolvendo o BPV-2 terem sido realizados em bexiga, a partir de casos de HE, existe uma ligação etiológica entre os compostos tóxicos da samambaia e o BPV-2. O efeito clastogênico dos componentes da samambaia tem sido avaliado in vitro e in vivo, mas a contribuição potencial da clastogenicidade do BPV ainda não foi esclarecida. A análise citogenética de células do sangue periférico de animais alimentados em pastagens infestadas com samambaia demonstra aumento significativo na freqüência de aberrações na estrutura dos cromossomos, quando comparados com animais em pastagens não infestadas. Como os linfócitos são células alvo da infecção latente pelo BPV, sugere-se que o vírus possa contribuir com a produção de anormalidades cromossômicas nestas células (MOURA et al., 1988; SANTOS et al., 1998).

O DNA do BPV-2 já foi detectado em tumores de bexigas, tanto de origem natural quanto induzido experimentalmente, sugerindo que o vírus presente na forma latente possa estar envolvido em transformações malignas. Acredita-se que a imunodepressão ativa o papilomavírus latente, provocando lesões prémalígnas e que o sinergismo entre o vírus e fatores co-carcinogênicos resulte na progressão tumoral. Esta reativação pode ocorrer pela imunodepressão causada por compostos da samambaia ou trauma físico, manifestando-se clinicamente por verrugas de pele e tumores de bexiga. Apesar das células dos fibropapilomas abrigarem múltiplas cópias do genoma do papilomavírus, que são facilmente detectadas por técnicas de hibridação, nenhum vírus maturo pode ser identificado por microscopia eletrônica a partir destas lesões. Os antígenos virais também não são detectados por métodos imunoistoquímicos aplicados em células infectadas (JARRETT et al., 1984; CAMPO; JARRETT, 1986; HOPKINS, 1986; CAMPO, 1987; CAMPO et al., 1992).

Campo et al. (1992), utilizando a hibridação de Southern Blot, encontraram o DNA do BPV-2 em $46 \%$ (7/15) dos casos naturais de tumores e em $69 \%$ (9/13) das lesões induzidas experimentalmente, sugerindo estreita associação entre este vírus e as neoplasias da bexiga de bovinos. Paralelamente, o DNA do BPV-2 também foi detectado em animais de experimento, mantidos em isolamento, que não foram inoculados com este vírus, ou que foram desafiados com um outro tipo de papilomavírus. Estes resultados sugerem que o BPV pode persistir na forma latente e ser ativado quando o animal é exposto a fatores co-carcinogênicos e imunodepressivos da samambaia. Em contraste, $20 \%$ dos animais controle também apresentaram o BPV-2. Estes dados são semelhantes aos descritos nos papilomas associados com o câncer genital em humanos.

Wosiacki (2002), utilizando a PCR em fragmentos de bexiga com lesões macroscópicas, detectou a presença do DNA do BPV-2 em 76,3\% (29/38) das amostras estudadas, sendo $62,5 \%(5 / 8)$ das amostras provenientes de bovinos com sinais clínicos de HE e $80 \%$ (24/30) provenientes de animais alimentados em pastagens com alta infestação pela samambaia. Neste estudo também foram incluídas 10 amos- 
tras de bexigas sem lesões macroscópicas, provenientes de animais assintomáticos e criados em regiões sem a infestação das pastagens pela samambaia. Todas as 10 amostras deste grupo, que constituiu o grupo controle, foram negativas na PCR.

\section{Diagnóstico laboratorial}

As principais viroses em animais podem ser diagnosticadas por técnicas convencionais de virologia como a cultura de células, a microscopia eletrônica e por reações sorológicas. Contudo, nenhuma destas técnicas é rotineiramente aplicada para detectar o papilomavírus, exceto a sorologia para o papilomavírus humano (HPV). Como os vírus da família Papillomaviridae não podem ser cultivados em sistemas de culturas celulares, o diagnóstico é baseado na identificação do DNA viral por meio de técnicas de hibridação e PCR; nos achados histológicos das lesões; e nos efeitos morfológicos sobre a citologia (BLOCH et al., 1997; GROSS; BARRASSO, 1999).

Entre as formas indiretas de diagnóstico do papilomavírus, o exame histopatológico permite a identificação de neoplasias intraepiteliais associadas a viroses potencialmente oncogênicas. No entanto, esta técnica não possibilita a identificação do tipo de vírus associado ao efeito citopático. A interpretação histológica também é dificultada quando as alterações vírus-associadas são mínimas, inviabilizando a identificação da infecção latente. A microscopia eletrônica e a imunofluorescência também podem ser utilizadas. A sorologia, que é uma técnica empregada apenas em estudos envolvendo o papilomavírus humano (HPV), tem grandes vantagens na rotina diagnóstica, no entanto, apresenta baixa especificidade e sensibilidade (JARRETT, 1978; CASON et al., 1993; GROSS; BARRASSO, 1999).

As formas diretas de diagnóstico do papilomavírus são atualmente os métodos de escolha para a sua detecção em esfregaços ou em fragmentos de tecidos. A imunoistoquímica pode detectar o revestimento protéico das partículas virais, po- rém não detecta o vírus em sua forma integrada ao genoma da célula hospedeira. Com isto, devido a pouca sensibilidade quando utilizada em amostras de tecido neoplásico, a imunoistoquímica não é o método de escolha para o diagnóstico da infecção pelo papilomavírus. Existem vários métodos moleculares para a detecção do DNA do papilomavírus, dentre eles, seis métodos são considerados principais: i) a hibridação por Southern blot, ii) hibridação por Dot blot, iii) hibridação in situ com filtro (FISH), iv) hibridação in situ (ISH), v) hibridação sanduíche em meio fluido (HCA) e vi) amplificação do DNA viral pela PCR (GROSS; BARRASSO, 1999; LANCELLOTTI et al., 2000).

A hibridação por Southern blot é considerada atualmente a técnica "padrão-ouro" para a detecção do genoma do papilomavírus. Este é um método valioso para a pesquisa, no entanto, existem dificuldades para a reprodução dos resultados. A hibridação por Dot blot é um método rápido e pouco dispendioso, porém as sondas comerciais disponíveis detectam apenas alguns poucos tipos do HPV. Atualmente esta técnica é utilizada para a triagem do HPV, assim como a FISH. A ISH é a única técnica que permite a localização do DNA ou RNA em células específicas ou regiões teciduais, porém somente detecta infecções virais com mais de 10 a 20 cópias do genoma viral por célula. Utilizando sondas comerciais disponíveis a ISH é substancialmente menos sensível que a técnica de Southern blot e a de Dot blot. A HCA é uma das mais antigas técnicas de hibridação de ácidos nucléicos, porém não distingue entre os tipos específicos do vírus e a sua aplicação como método de pesquisa é limitada, sendo que sua utilização é mais viável na rotina clínica (GROSS; BARRASSO, 1999).

A PCR é uma técnica que permite a amplificação enzimática in vitro de ácidos nucléicos, DNA ou RNA, que podem ser visualizados por eletroforese. A PCR tornou-se a mais adequada técnica para a detecção do papilomavírus devido à alta sensibilidade e especificidade e por não requerer o cultivo do vírus. Diferentes seqüências de oligonucleotídeos 
iniciadores específicos (primers) foram desenhados com o objetivo de identificação do BPV-1, do BPV2, do BPV-4 e do BPV-5 (GAUKROGER et al., 1991; TEIFKE; WEISS, 1991; OTTEN et al., 1993; BLOCH et al., 1997; SANTOS et al., 1998; WOSIACKI, 2002).

\section{Vacinas}

Segundo Hopkins (1986), se o BPV-2 for considerado na etiologia da indução de tumores na $\mathrm{HE}$, futuras possibilidades de imunoprofilaxia destas lesões podem incluir o uso de vacinas, que teriam grande importância econômica para regiões de pecuária bovina onde esta doença constitui um problema sanitário.

A pesquisa de vacinas para o papilomavírus é dificultada pela sua incapacidade de replicação in vitro em culturas celulares e pela sua dificuldade de adaptação em culturas de tecidos. Sucessos na profilaxia e também na rejeição de tumores epidermais e do trato digestório foram obtidos em bovinos que receberam tanto vacinas convencionais quanto vacinas produzidas por engenharia genética. Inicialmente, dois tipos de vacinas foram considerados: i) vacinas profiláticas que produziriam anticorpos vírus-neutralizantes prevenindo a infecção e ii) vacinas terapêuticas que induziriam a regressão das lesões já estabelecidas antes do início da progressão maligna (CAMPO, 1991; CAMPO; JARRETT, 1994).

O primeiro estudo com a vacinação contra diferentes tipos de BPV foi realizado por Jarrett et al. (1990), que sugeriram que a imunidade para o papilomavírus é tipo-específica. A clonagem das proteínas L1 e L2 do BPV-2 foi empregada para a produção de vacinas tanto profiláticas quanto terapêuticas (JARRETT et al., 1991; CAMPO, 1995). As vacinas compostas pela proteína L1 preveniram a formação de tumores quando administradas antes do desafio. Já as vacinas compostas pela proteína L2 promoveram a rejeição dos tumores, independente se a administração foi realizada anterior ou posteriormente ao desafio. Animais vacinados com a proteína $\mathrm{L} 1$, mas não com a L2, responderam rapidamente com a produção de anticorpos séricos neutralizantes, mostrando que este peptídeo contém epitopos que especificamente ativam os linfócitos B. A grande infiltração de linfócitos nos tumores dos animais vacinados com a proteína L2 sugere que os determinantes antigênicos deste peptídeo são mais específicos na ativação de linfócitos T.

A vacina autógena, preparada com homogeneizado de verrugas, tem sido usada em bovinos e outras espécies animais. Em alguns casos as lesões podem regredir espontaneamente, mas alguns experimentos já indicaram os efeitos positivos desta imunização. Outras possibilidades de vacinas incluem: i) vacina com vírions purificados, administrada por via intramuscular, que protege os animais de subseqüentes desafios com o vírus homólogo, ii) vacina com partículas semelhantes ao vírus (VLPs) preparadas por clonagem dos genes das principais proteínas virais em vetores eucariotas e, iii) vacina de DNA. Porém, todos os estudos relativos ao desenvolvimento de vacinas contra o BPV ainda estão em fase inicial (NICHOLLS; STANLEY, 2000).

\section{Perspectivas}

As perspectivas de trabalhos futuros com a HE, além do desenvolvimento de imunógenos, fundamentam-se na avaliação de sistemas de diagnóstico, e em estudos in vitro e in vivo que possam elucidar a patogenia e a inter-relação entre o BPV2 e compostos tóxicos presentes na samambaia, responsáveis pelo desenvolvimento de neoplasias de bexiga em bovinos. 


\section{Referências}

BLOCH, N.; BREEN, M.; SPRADBROW, P.B. Genomic sequences of bovine papillomaviruses in formalin-fixed sarcoids from Australian horses revealed by polymerase chain reaction. Vet. Microbiol., Amsterdam, v.41, n.1-2, p.163-172, Jul. 1994.

BLOCH, N. et al. Identification of papillomavirus in scrapings from bovine warts by use of the polymerase chain reaction. Vet. Res. Commum., Dordrecht, v.21, n.1, p.63-68, Jan. 1997.

BRINGUIER, P. et al. Animal model bracken fern: induced bladder tumors in Guinea pigs: a model for human neoplasia. Am. J. Pathol., Bethesda, v.447, n.3, p.858-868, Sept. 1995.

CAMPO, M.S. Papillomas and cancer in cattle. Can. Surv., New York, v.6, n.1, p.39-54, 1987.

. Vaccination against papillomavirus. Can. Cells, New York, v.3, n.11, p.421-426, Nov. 1991.

Infection by bovine paillomavirus and prospects for vaccination. Trends Microbiol., Limerick, v.3, n.3, p.92-7, mar. 1995.

Review bovine papillomavirus and cancer. Vet. J., London, v.154, n.3, p.175-188, Nov. 1997.

CAMPO, M.S.; JARRETT, W.F. Papillomavirus infection in cattle: viral and chemical cofactors in naturally occurring and experimentally induced tumours. Ciba Found Symp., Chichester, n.120, p.117-135, 1986.

CAMPO, M.S.; JARRETT, W.F. Vaccination against cutaneous and mucosal papillomavirus in cattle. Ciba Found Symp., Chichester, v.187, p.61-73, 1994.

CAMPO, M.S. et al. Association of bovine papillomavirus type 2 and bracken fern with bladder cancer in cattle. Can. Res., Philadelphia, n.52, n.24, p.6898-6904, Dec. 1992.

CAMPO, M.S. et al. Experimental reprodution of the papilloma-carcinoma complex of the alimentary canal in cattle. Carcinogenesis, Oxford, v.15, n.8, p.1597-1601, Aug. 1994.

CASON, J. et al. Mapping of linear B cell epitopes on capsid proteins of bovine papillomavirus: identification of three external type-restricted epitopes. J. Gen. Virol.,Reading, v.74, n.12, p.2669-2677, Dec. 1993.

DURÃO, J.F.C. et al. Aspectos anatomopatológicos e clínicos da hematúria enzoótica dos bovinos. Rev. Port. Cienc. Vet., Lisboa, v.90, n.515, p.132-137, Jul./Set. 1995.
GAUKROGER, J. et al. Malignat transformation of a papilloma induced by bovine papillomavirus type 4 in the nude mouse renal capsule. J. Gen. Virol., Reading, v.72, n.5, p.1165-1168, May 1991.

GAVA, A. Intoxicações por plantas de ação antihematopoética e mutagênica. In: RIET-CORREA, F.; SCHILD, A.L.; MÉNDEZ, M.D.C. Intoxicações por plantas e micotoxicoses em animais domésticos. Buenos Aires: Editorial Hemisfério Sur, 1993. p.247-258.

GROSS, G.E.; BARRASSO, R. Infecção por papilomavírus humano:atlas clínico de HPV. Porto Alegre: Artmed, 1999. 45p.

HOPKINS, A. Bracken (Pteridium aquilinum): its distribution and animal health implications. Br. Vet. J. Bailliere Tindall , v.146, n.4, p.316-326, Jul./Aug. 1990.

HOPKINS, N.C.G. Aetiology of enzootic haematuria. Vet. Rec., London., v.118, n.26, p.715-717, Jun. 1986.

JARRETT, W.F. High incidence area of cattle cancer with a possible interaction between an environmental carcinogen and a papilloma virus. Nature, London, n.274, p.215-217, Jul. 1978.

JARRETT, W.F. et al. Alimentary fibropapilloma in cattle: a spontaneous tumor, nonpermissive for papillomavirus replication. J. Nat. Can. I., Bethesda, v.73, n.2, p.499504, Aug. 1984.

JARRET, W.F. et al. Studies on vaccination against papillomaviruses: the immunity after infection and vaccination with bovine papillomaviruses of different types. Vet. Rec.,London, v.126, n.19, p.473-475, May 1990.

JARRETT, W.F. et al. Studies on vaccination against papillomaviruses: prophylactic and therapeutic vaccination with recombinant structural proteins. Virol., New York, v.184, n.1, p.33-42, Sep. 1991.

LANCELLOTTI, C.L.P. et al. Diagnóstico laboratorial. In: CARVALHO, J.J.M.; OYKAWA, N.(Eds). Consenso Brasileiro de HPV, 1., 1999, São Roque. São Paulo: BG Cultural, 2000. p.45-60.

MONOGHAN, M.L.; BOY, M.G. Sistema renal dos ruminante. In: SMITH, B.P. Tratado de medicina interna de grandes animais. São Paulo: Manole, 1993. p.888-900.

MOURA, J.W. et al. Chromosome aberrations in cattle raised on bracken fern pasture. Experientia, Basel, v.44, n.9, p.785-788, Sep. 1988.

NGOMUO, A.J.; JONES, R.S. Cytotoxicity studies of quercetin, shikimate, cyclohexanecarboxylate and ptaquiloside. Vet. Hum. Toxicol., Manhattan, v.38, n.1, p.14-18, Feb. 1996. 
NICHOLLS, P.K.; STANLEY, M.A. The immunology of animal papillomaviruses. Vet. Immun. Immunopathol., Amsterdam, v.73, n.2, p.101-127, 2000.

NIELSEN, S.W.; MOULTON, J.E. Tumors of the urinary system. In: MOULTON, J.E. Tumors in domestic animals. 3.ed. Los Angeles: University of California, 1990. p.458-478.

OLSON, C. et al. Urinary bladder tumor induced by a bovine cutaneous papilloma agent. Can. Res., Toronto, n.19, p.779-783, Aug. 1959.

OTTEN, N. et al. DNA of bovine papillomavirus type 1 and 2 in equine sarcoids: PCR detection and direct sequencing. Arch. Virol., Wien, v.132, n.1-2, p.121131, 1993.

PACHAURI, S.P.; SHARMA, U.K.; JOSHI, H.C. Note on pathological studies on the urinary bladder tumours of cattle with chronic haematuria. Int. J. Anim. Sci., Sonepat, v.51, n.9, p.898 - 900, Sep. 1981.

POLACK, E.W. Toxicidade da Pteridium aquilinum (L.) Kuhn no Estado do Paraná. 1990. 102 f. Dissertação (Mestrado) Universidade Federal do Paraná, Curitiba, 1990.

RAJENDRAN, M.P. et al. Experimental production of enzootic bovine haematuria with braken fern. Indian Vet. J., Bangalore, n.60, p.173-178, Mar. 1983.

REDDY, A.L.; FIALKOW, P.J. Papillomas induced by initiation-promotion differ from those induced by carcinogen alone. Nature, London, v.304, n.7, p.69-71, Jul. 1983.
SANTOS, R.C.S. et al. Bovine papillomavirus transmission and chromosomal aberrations: on experimental model. J. Gen. Virol., Reading, v.79, n.9, p.21272135, Sep. 1998.

SCHUCH, L.F.D. Papilomatose bovina. In: RIETCORREA, F.; SCHILD, A.L.; MÉNDEZ, M.D.C. Doenças de ruminantes e eqüinos. Pelotas: Ed. Universitária/ UFPel, 1998. p.115-118.

STRINGFELLOW, D. A. et al. Virology. Michigan: Upjohn, 1988. 139p.

TEIFKE, J.P.; WEISS E. Detection of bovine papillomavirus DNA in equine sarcoids using the polymerase chain reaction. Berl. Munch. Tierarztl. Wochenschr., Berlin, v.104, n.6, p.185-187, Jun. 1991.

TOKARNIA, C.H.; DÖBEREINER, J.; CANELLA, C.F.R. Ocorrência da intoxicação aguda pela samambaia (Pteridium aquilinum (L.) Kuhn) em bovinos no Brasil. Pesqui. Agropecu. Bras., Brasília, n.2, p.329-336, 1967.

THOMSON, R.G. Patologia veterinária especial. São Paulo: Manole, 1990. 752p.

VAN REGENMORTEL, M.H.V. et al. Virus taxonomy: the classification and nomenclature of viruses. The Seventh Report of the International Committee on Taxonomy of Viruses . San Diego: Academic Press, 2000.

WOSIACKI, S.R. Papilomavírus bovino tipo 2 em bexiga de bovinos na hematúria enzoótica: detecção utilizando a reação em cadeia pela polimerase e estudo histopatológico. 2002. 110 f Dissertação (Mestrado em Sanidade Animal) - Centro de Ciências Agrárias, Universidade Estadual de Londrina, Londrina. 